\title{
Intestinal microbiota: a novel perspective in colorectal cancer biotherapeutics
}

This article was published in the following Dove Press journal:

OncoTargets and Therapy

\author{
Chenbo Ding ${ }^{1,2}$ \\ Wendong Tang' \\ Xiaobo Fan' \\ Guoqiu Wu',2 \\ 'Medical School of Southeast \\ University, Nanjing, Jiangsu Province, \\ People's Republic of China; ${ }^{2}$ Center \\ of Clinical Laboratory Medicine, \\ Zhongda Hospital, Southeast \\ University, Nanjing, Jiangsu Province, \\ People's Republic of China
}

\begin{abstract}
It is believed that genetic factors, immune system dysfunction, chronic inflammation, and intestinal microbiota (IM) dysbiosis contribute to the pathogenesis of colorectal cancer (CRC). The beneficial role played by the direct regulation of IM in inflammatory bowel disease treatment is identified by the decreased growth of harmful bacteria and the increased production of anti-inflammatory factors. Interestingly, gut microbiota has been proven to inhibit tumor formation and progression in inflammation/carcinogen-induced CRC mouse models. Recently, evidence has indicated that IM is involved in the negative regulation of tumor immune response in tumor microenvironment, which then abolishes or accelerates anticancer immunotherapy in several tumor animals. In clinical trials, a benefit of IM-based CRC therapies in improving the intestinal immunity balance, epithelial barrier function, and quality of life has been reported. Meanwhile, specific microbiota signature can modulate host's sensitivity to chemo-/radiotherapy and the prognosis of CRC patients. In this review, we aim to 1) summarize the potential methods of IM-based therapeutics according to the recent results; 2) explore its roles and underlying mechanisms in combination with other therapies, especially in biotherapeutics; 3 ) discuss its safety, deficiency, and future perspectives.
\end{abstract}

Keywords: intestinal microbiota, colorectal cancer, biotherapeutic, immune response

\section{Introduction}

Colorectal cancer $(\mathrm{CRC})$ is one of the leading causes of cancer mortality in the world, ${ }^{1}$ being ranked fifth most lethal neoplasia in China. ${ }^{2}$ In 2015, the National Cancer Center of China estimated that approximately 489,000 new CRC cases will be diagnosed in China, with more than 246,000 Chinese expected to die of it. ${ }^{2}$ The pathologic process of $\mathrm{CRC}$ is from normal epithelium to adenomatoid polyps, and finally to adenocarcinoma. Depending on its etiology and pathogenesis, CRC mainly divides into sporadic, hereditary, and inflammatory CRC. As part of a multistep process, genetic factors, life styles, diet habits, and chronic inflammation are thought to contribute to the occurrence and progression of CRC through the accumulation of a variety of genetic and epigenetic alterations..$^{3-7}$ Notably, a number of studies have shown that the 5-year accumulative cancerization risk of inflammatory bowel disease (IBD) is up to $33 \%-54 \% .^{8-10}$ In addition, patients with IBD have an increased $2-4$ times risk of developing CRC than the normal. ${ }^{11}$ Although multiple mutations are needed for both inflammatory and sporadic CRC, IBD-CRC model could accelerate hypermethylation, and chromosomal and microsatellite instability, and alter the stability and diversity of intestinal microbiota (IM). ${ }^{6,10,12}$ It is widely identified that intestinal bacteria dysbiosis is associated with the loss of epithelial barrier function, the pathogenesis of IBD, and colitis-associated CRC. ${ }^{13,14}$ 
Human intestinal microbes contain at least 1,000 species, which are essential for digesting food, controlling intestinal epithelial homeostasis, intestinal development, and human health. ${ }^{15}$ Intestinal mucosal symbiotic bacteria increase intestinal stability and inhibit intestinal colonization by pathogens. When the balance of IM is broken, intestinal mucosal barrier and innate immunity function are reduced, and the relative pathogenic factors are increased so as to cause chronic inflammatory and infectious diseases. Interestingly, a new study indicated that IBD susceptibility is attributed to specific bacteria communities and that manipulation of the IM alters the induction and/or perpetuation of T-cell-induced colitis. ${ }^{16}$ The important modulation role of gut microbiota in inflammation-induced tumorigenesis was evident through the inhibition of tumor formation found in several CRC mouse models. ${ }^{17,18}$ In addition, numerous bacterial species such as Bacteroides fragilis, Fusobacterium nucleatum, and Peptostreptococcus stomatis have been found to have significant association with human CRC samples. ${ }^{19}$ A study first assessed that fecal microbiota also could directly promote intestinal carcinogenesis in germ-free mice and mice given a carcinogen through gavage of stool samples from patients with CRC. ${ }^{20}$ More recently, tumorprone mice cocolonized with enterotoxigenic $B$. fragilis (ETBF) and Escherichia coli (expressing colibactin) showed increased levels of inflammation markers in the colon and DNA damage in colonic epithelium with faster tumor onset and greater mortality, compared to mice with either bacterial strain alone. ${ }^{21}$ Mechanistically, gut microbiota may induce CRC by numerous processes, including the generation of toxic metabolites and genotoxic biosynthesis, the changes in DNA damage and chromosome instability, and an effect on epithelial cells proliferation and apoptosis. ${ }^{22-24}$ However, the accurate molecular mechanism of gut microbiota-induced CRC remains unknown. "Alpha-bug", 25 "Driver-passenger", ${ }^{26}$ and "Integrated function" 27 are the three major carcinogenic theories for IM-mediated CRC. Among these patterns, Gallimore and Godkin perfectly described the combined reaction of gut microecology, chronic inflammation, and intestinal mucosal barrier in the occurrence and progression of CRC.

At present, the radical surgery is the only probable cure for CRC, but the overall outcome for local and distant metastatic patients is barely ameliorated. Traditional chemo/ radiotherapies have improved the survival rate of these patients, and reduced the recurrence rate in a certain extent. ${ }^{28}$ However, researchers must develop alternative methods or drugs to combat the problem that, due to long-term chemo-/ radiotherapy, an increasing number of patients have the serious therapy resistance and the occurrence of cancer metastasis. Notably, $\sim 35 \%$ of patients with CRC have metastatic disease at diagnosis, which is a major cause of CRC-associated mortality. ${ }^{29}$ Obviously, the prevention and early diagnosis is of great significance in the treatment and prognosis of CRC patients. Chronic inflammation is an important risk factor for intestinal carcinogenesis. Thus, effective prevention and/or treatment of IBD can significantly reduce the incidence of colitis-associated CRC. Probiotics and fecal microbiota transplantation (FMT) are being increasingly employed to treat IBD through the direct regulation of gut microbiome. In addition, probiotics and FMT can enhance the secretion of anti-inflammatory factors, reduce the growth of harmful bacteria by reconstructing intestinal mucosal barrier and immune system function, and thus play a preventive and therapeutic role in IBD. ${ }^{30,31}$ Currently, probiotics and FMT have been regarded as a safe treatment strategy compared to traditional treatment with significant toxicity, high recurrence rates, and poor outcomes. Exhilaratingly, a recent study demonstrated for the first time that patients with gastric carcinoma exhibit a dysbiotic microbial community with genotoxic potential, which is distinct from that of patients with chronic gastritis. ${ }^{32}$ Besides, present studies indicated that the structure and characteristics of the gut microbiota are markedly altered in CRC. Further population-based epidemiologic study is necessary to reveal the characteristics of intestinal microbiome in ultraearly CRC, which might provide some novel prophylactic and early diagnosis strategies for CRC patients.

Different from the traditional treatments, biotherapeutic is a new avenue to target cancer mainly through mobilizing the body's natural anticancer ability and restoring the balance of the internal microenvironment. Until now, numerous studies have been successfully conducted for IM-based CRC therapies in animal models by using pro-/prebiotics. ${ }^{33,34}$ Additionally, targeted gut microbiome might be an effective strategy for preventing the progression of inflammation-driven $\mathrm{CRC}$ under antibiotic treatment. ${ }^{35}$ Moreover, IM has been found to play a significant modulation role in immune-checkpoint inhibitors-mediated anticancer immune response. ${ }^{36,37}$ In clinical trials, pro-/prebiotics are widely used to reduce postoperative infections, and improve bowel immune system and epithelial barrier function in CRC patients. ${ }^{38-40}$ Meanwhile, it has identified that the specific intestinal bacteria could affect chemo-/radiotherapy sensitivity in CRC patients. ${ }^{41,42}$ Based on these evidences, IM turns out to be encouraging in clinical application and shows a promising target in CRC biotherapeutics. Here, we mainly review our 
emerging understanding of IM-based therapies in current applications for CRC patients, and discuss its potential in biotherapeutics. The general concerns of IM-based CRC therapies include underlying methods, the novel roles in combination with other treatments, especially in immunotherapy, and analysis of safety, efficacy, and future perspectives.

\section{IM is closely linked to CRC pathologies}

Recently, it has been demonstrated that gut microbiota contributes to the development of CRC through altering intestinal bacterial biofilms, microenvironment homeostasis, and immune reaction. Bacterial biofilms consist of a higher-order level of spatial organization of multi-organism structures in mucosal microbial communities in the human intestine, and act as the first line of defense against invading microbesinduced inflammatory responses and the production of genotoxic bacterium-derived compounds. ${ }^{43-45}$ Alteration of colonic mucosal biofilms in the colon tissue microenvironment is a distinct feature of proximal CRC. ${ }^{43}$ Bacterial biofilms were associated with diminished colonic epithelial cell E-cadherin and increased crypt epithelial cell proliferation in normal colon mucosa. ${ }^{43}$ Comparative researches of the stool samples of healthy individuals and CRC patients found a significant difference in bacterial genera. ${ }^{19,46}$ It had shown that a reduction of biodiversity and richness of microbial community with an increase in Fusobacterium, Peptostreptococcus, Bacteroides, Eubacterium, Proteobacteria, Prevotella, and Clostridium species were associated with CRC patients. ${ }^{19,46-50}$ Among these bacteria, $F$. nucleatum was found to contribute to serrated pathway, adenoma-carcinoma sequence, and pathologic progression in CRC. ${ }^{51,52}$ Further study had identified that $F$. nucleatum promoted proliferation of CRC cells and tumor development in mice by activating toll-like receptor (TLR)/myeloid differentiation primary response gene 88 (MyD88)/nuclear factor- $\kappa \mathrm{B}$ signaling. ${ }^{53}$ Notably, infection with $F$. nucleatum animalis in colorectal tissue could induce inflammatory response and promote CRC development. ${ }^{54}$ In addition, $F$. nucleatum had been shown to expand myeloid-derived immune cells, which suppressed T-cell proliferation and induced T-cell apoptosis in CRC. ${ }^{55}$ These results suggest that gut microbiota plays a great role in the initiation and progression of CRC.

\section{Potential therapeutics for IM Oral probiotics}

Probiotics are live microorganisms, which confer a beneficial role in cancer prevention and treatment by reducing harmful bacterial translocation, promoting intestinal immune barrier function and antipathogenic activity. ${ }^{56,57}$ Currently, Lactobacillus, Bifidobacteria, Saccharomyces boulardii, and Bacillus coagulans are the most common products of microbiota used as probiotics. ${ }^{56,57}$ In addition, synbiotics, as a conjunction between prebiotics and probiotics, are used to improve the survival of the probiotic bacteria during the passage through the upper intestinal tract. ${ }^{56}$

Several studies had indicated the intelligible effects of the cytoplasmic extracts or cell-free supernatants from probiotic products or strains in inhibition of CRC cells proliferation and prevention of malignant transformation in vitro. ${ }^{58-60}$ Notably, a recent paper ${ }^{61}$ had revealed that the combined application of Propionibacterium freudenreichii and tumor necrosis factor (TNF)-related apoptosis-inducing ligand (TRAIL) increased proapoptotic gene expression and decreased antiapoptotic gene expression in CRC cells, suggesting that $P$. freudenreichii has potential as a new adjuvant for TRAIL-based CRC therapy. In experimental models, probiotics could obviously decrease the incidence and development of carcinogen-induced CRC. ${ }^{33,62-67}$ Interestingly, two reports demonstrated that probiotics exhibited an inhibitory role against colorectal tumorigenesis in adenomatous polyposis coli mutation mice. ${ }^{68,69}$ In addition, murine models of colorectal carcinoma fed with the engineered microbes and the cruciferous vegetable diet displayed significant tumor regression and reduced tumor occurrence. ${ }^{70}$ In CRC patients who were submitted to surgery, oral probiotics effectively reduced the tumor recurrence rate, and protected the intestinal mucosa physical and biologic barrier. ${ }^{71,72}$ According to the researches, either dietary synbiotics or yogurt attenuated the CRC risk factors. ${ }^{40,73}$ Moreover, it had demonstrated that Lactobacillus casei could prevent atypia of colorectal tumors. ${ }^{74}$ To date, 24 clinical trials of pro-/synbiotics therapies had been published and shown a favorable benefit for CRC patients (Table 1). The outcomes of these studies are highlighted as a possible alternative or adjuvant to conventional methods in CRC therapeutic.

However, four clinical reports indicated that pro-/ synbiotics had no measurable effect on gut barrier function, inflammatory response, and complications after CRC surgery. ${ }^{94-97}$ In addition, although synbiotic supplementation with Bifidobacterium lactis and resistant starch induced unique changes in fecal microflora, it did not significantly alter any other fecal, serum, or epithelial biomarkers of CRC patients. ${ }^{98}$ These results allow us to consider the patient's family history and lifestyle, including diet, smoking, and other factors before treatment with pro-/synbiotics. In line 
Table I Clinical applications and outcomes of pro-/synbiotics formulations in CRC therapy

\begin{tabular}{|c|c|c|c|}
\hline Pro-/synbiotics & Outcome & Subjects & Reference \\
\hline $\begin{array}{l}\text { Lactobacillus rhamnosus, Bifidobacterium } \\
\text { lactis, inulin }\end{array}$ & $\begin{array}{l}\text { A reduction of colorectal proliferation and an } \\
\text { improvement of epithelial barrier function }\end{array}$ & $\begin{array}{l}\text { CRC and } \\
\text { polypectomized patients }\end{array}$ & 40 \\
\hline Lactobacillus casei & Preventing atypia of colorectal tumors & CRC removed patients & 74 \\
\hline $\begin{array}{l}\text { Lactobacillus, Bifidobacterium, } \\
\text { Thermophilus, Enterococcus faecium }\end{array}$ & $\begin{array}{l}\text { A feasible approach to protect patients against the risk of } \\
\text { therapy-induced diarrhea }\end{array}$ & $\begin{array}{l}\text { Chemo-/radiotherapy } \\
\text { CRC patients }\end{array}$ & $75-77$ \\
\hline $\begin{array}{l}\text { Bifidobacterium, Lactobacillus acidophilus } \\
\text { Lactobacillus, Pediococcus pentosaceus, }\end{array}$ & $\begin{array}{l}\text { A beneficial effect on the intestinal barrier function and a } \\
\text { reduction of infection complication }\end{array}$ & $\begin{array}{l}\text { Preoperative therapy of } \\
\text { CRC patients }\end{array}$ & $78-80$ \\
\hline $\begin{array}{l}\text { Leuconostoc mesenteroides, fermentable } \\
\text { fibers }\end{array}$ & $\begin{array}{l}\text { A beneficial effect on the intestinal barrier function and a } \\
\text { reduction of infection complication }\end{array}$ & $\begin{array}{l}\text { Preoperative therapy of } \\
\text { CRC patients }\end{array}$ & 81 \\
\hline $\begin{array}{l}\text { Lactobacillus, Bifidobacterium, } \\
\text { E. faecium, Saccharomyces boulardii }\end{array}$ & $\begin{array}{l}\text { An improvement of gut mucosal barrier and a reduction } \\
\text { of infectious complications }\end{array}$ & $\begin{array}{l}\text { Perioperative therapy of } \\
\text { CRC patients }\end{array}$ & $71,82-86$ \\
\hline $\begin{array}{l}\text { P. pentosaceus, L. mesenteroides, } \\
\text { Lactobacillus, multiplant fibers }\end{array}$ & $\begin{array}{l}\text { A protective effect in preventing a postoperative } \\
\text { inflammatory response }\end{array}$ & $\begin{array}{l}\text { Perioperative therapy of } \\
\text { CRC patients }\end{array}$ & 87 \\
\hline $\begin{array}{l}\text { Lactobacillus, Bifidobacterium, } \\
\text { Streptococcus thermophiles, } \\
\text { oligofructose }\end{array}$ & $\begin{array}{l}\text { A reduction in the prevalence of fecal enterobacteriaceae } \\
\text { and bacterial translocation, but not in inflammatory } \\
\text { response or septic morbidity }\end{array}$ & $\begin{array}{l}\text { Perioperative therapy of } \\
\text { CRC patients }\end{array}$ & 88 \\
\hline $\begin{array}{l}\text { Lactobacillus, Bifidobacterium, fruit } \\
\text { oligosaccharides }\end{array}$ & $\begin{array}{l}\text { An increased production of interferon-gamma, and minor } \\
\text { stimulatory effects on the systemic immune system }\end{array}$ & $\begin{array}{l}\text { Postoperative therapy of } \\
\text { CRC patients }\end{array}$ & $\begin{array}{l}38 \\
89\end{array}$ \\
\hline $\begin{array}{l}\text { Lactobacillus, Bifidobacterium, fruit } \\
\text { oligosaccharides }\end{array}$ & $\begin{array}{l}\text { A beneficial effect of symbiotic supplementation, and } \\
\text { CRP reduction in meantime }\end{array}$ & $\begin{array}{l}\text { Postoperative therapy of } \\
\text { CRC patients }\end{array}$ & \\
\hline $\begin{array}{l}\text { Lactobacillus plantarum, } \\
\text { L. acidophilus- I I, Bifidobacterium } \\
\text { longum-88 }\end{array}$ & $\begin{array}{l}\text { A reduction of the serum zonulin level, the rate of } \\
\text { postoperative septicemia, and a maintainment of the liver } \\
\text { barrier }\end{array}$ & $\begin{array}{l}\text { Perioperative therapy } \\
\text { of colorectal liver } \\
\text { metastases }\end{array}$ & 90 \\
\hline E. faecium M-74 & $\begin{array}{l}\text { An effective and promising method for elimination of } \\
\text { pathogenic bacteria in the case of IBD and CRC }\end{array}$ & $\begin{array}{l}\text { CRC and IBD patients, } \\
\text { healthy subjects }\end{array}$ & 91 \\
\hline Bifidobacterium triple viable capsule & $\begin{array}{l}\text { An inhibited role in small intestinal bacterial overgrowth } \\
\text { with alleviating its symptoms }\end{array}$ & $\begin{array}{l}\text { Gastric cancer and CRC } \\
\text { patients }\end{array}$ & 92 \\
\hline Lactobacillus, Bacillus natto & An improvement of bowel symptoms and quality of life & $\begin{array}{l}\text { Postoperative therapy of } \\
\text { CRC, and CRC survivors }\end{array}$ & 39,93 \\
\hline
\end{tabular}

Abbreviations: CRC, colorectal cancer; IBD, inflammatory bowel disease; CRP, C-reactive protein.

with the above comment that further and in-depth researches are taken to gain a keen understanding of their clinical value in CRC patients.

\section{Providing prebiotics}

In 2016, the International Scientific Association for Probiotics and Prebiotics had updated the definition of a prebiotic: a substrate that is selectively utilized by host microorganisms conferring a health benefit, not confined to traditionally considered fructans (fructooligosaccharides and inulin) and galactans (galactooligosaccharides)-based carbohydrate. ${ }^{99}$ This new definition will help broaden the scope of prebiotics in research studies and clinical applications. Despite that both prebiotics and probiotics can improve the integrity of the epithelial layer of the intestines, they can also increase the resistance against pathogenic colonization, a completely different model. Probiotics as new bacteria enter the human intestinal tract and then improve intestinal microecology, while prebiotics play a direct regulated role in gut microbiota. Interestingly, a present study suggested that polyphenols from green tea, oolong tea, and black tea could modulate the IM and generate short-chain fatty acids, and contribute to the improvements of human health. ${ }^{100}$ There is evidence that the consumption of prebiotics may inhibit colorectal carcinogenesis in culture and animal models. ${ }^{34,101-104}$ In healthy subjects, intervention trials indicated that palm, blackcurrant products, butyrylated starch, and wheat bran extract have a possible protective role in decreasing CRC risk. ${ }^{105-108}$ In addition, prudent diet (rich in whole grains and dietary fiber) was related with a lower risk of $F$. nucleatum-positive CRCs, but not with negative ones, suggesting that the association of dietary patterns with CRC significantly differed by tissue F. nucleatum status. ${ }^{109}$ By contrary, data from a Phase II chemoprevention trial did not provide convincing evidence of CRC risk reduction from 6-month interventions with prebiotic dietary fiber. ${ }^{110}$ Currently, the clinical application of prebiotics in CRC treatment mainly focuses on combination with probiotics as synbiotics (Table 1), and the most of the outcomes are exciting and positive.

Noticeably, pre-/synbiotics therapies from clinical studies have not shown satisfactory results in all CRC population, which leads us to take into account its imperfect reasons. 
The human gut microbiome can be regarded as a "super organism" or "second genome" that regulates the host's metabolism and immune system. So, does it also have positive and negative feedback regulation or self-regulation model similar to the human genome? If the answer is yes, then what is the molecular mechanism? In human genome, multiple genes and its related signaling exhibit a double effect in different human diseases; for example, c-Jun N-terminal kinase and p38 $\alpha$ signaling pathways play a "good-cop and bad-cop" role in inflammatory and epigenetic modificatory diseases or tumorigenesis. ${ }^{111,112}$ Interestingly, Lactobacillus gasseri could increase transforming growth factor (TGF)- $\beta 1$ mRNA and protein secretion in colonic cell lines. ${ }^{113}$ It is well identified that TGF- $\beta$ plays a contradictory role in premalignant and cancer cells, and the mechanism of gut microbiota affecting TGF- $\beta$ levels in the development and progression of malignancies is still obscure. Such results invite the plausible hypothesis that 1) as a result of the different pathogenesis of inflammation, genetic mutations, and epigenetic modifications-associated $\mathrm{CRC}$, whether pre-/synbiotics have dual function in these distinct patients; 2) there are some specific species in IM, maybe not pathogenic bacteria, which could also reduce/suppress the regulatory function of pre-/synbiotics, or even "kidnap" pre-/synbiotics and then participate in the procession of CRC under certain conditions; 3 ) although pre-/synbiotics do play an important role in modulation of immune development and function, and balance of IM, in some patients with severe gut microbiota dysbiosis may be beyond the control of prebiotics itself. If only these issues are fully investigated, can CRC be cured or controlled with simple daily use of pre-/synbiotics in the future.

\section{Drugs intervention}

Antibiotics are invaluable weapons to fight IBD, but longterm antibiotic use is associated with an increased risk of colorectal adenoma by altering the composition and functions of IM. ${ }^{114}$ It has been identified that gut microbiota is required for heme-induced epithelial hyperproliferation and hyperplasia because of the capacity to reduce mucus barrier function in colon. ${ }^{115}$ However, the suppression of microbiota by antibiotics was related to a reduction in crypt height and heme-induced colorectal carcinogenesis in rats. ${ }^{116}$ In addition, antibiotic drugs such as anisomycin, prodigiosin, and salinomycin had shown an inhibiting function in the growth of colorectal carcinoma cells by targeting different molecular mechanisms. ${ }^{117-119}$ In inflammation-driven CRC mouse, targeted IM turned out an effective strategy for preventing the development of CRC under antibiotic treatment..$^{35}$
Interestingly, a study by Hamoya et al ${ }^{120}$ suggested that erythromycin is useful as a chemopreventive agent and suppresses intestinal polyp development in mice, in part by attenuating local inflammation. Furthermore, treatment of mice bearing a colon cancer xenograft with the antibiotic metronidazole reduced Fusobacterium load, cancer cell proliferation, and overall tumor growth, which indicated antimicrobial interventions as a potential treatment for patients with Fusobacterium-associated CRC. ${ }^{121}$ Now, it is not clear whether these drugs found in natural microorganisms exert anti-CRC effects by affecting the function and balance of gut microbiota, but there is a viable way to explore and develop novel antibiotics or antibiotic peptides based on human IM itself. In the latest studies, the fingerprint of the human gastrointestinal (GI) tract microbiota aimed to study many complex bacterial ecosystems, which might push the development of narrow spectrum antibiotics and the application in CRC treatment, and formulate systems pharmacology and personalized therapeutics. ${ }^{122,123}$

Moreover, a series of medications, including celecoxib, berberine, isoliquiritigenin, and curcumin, had been found to decrease the incidence of colorectal tumorigenesis by modulating the IM. ${ }^{124-127}$ Another potential agent might be the herbal medicines, such as ginseng and astragalus, which are metabolized extensively by IM and could act as adjuvants for cancer chemoprevention. ${ }^{128}$ Although these medicines are only used in mice models for this study, evidently it is feasible that the locus could be an attractive method for IM-based strategies.

\section{FMT}

FMT is a method of fecal suspension from healthy donors into the GI tract of individuals to cure specific diseases by reconstructing the normal function and the immune system of IM. As early as 1958, Eiseman et al ${ }^{129}$ had first used FMT in mainstream medicine for the treatment of pseudomembranous colitis. In recent years, FMT is no longer considered an "alternative", and is now gaining mainstream acceptance as a valuable biotherapeutic; although still poorly understood, it is used to treat GI diseases including IBD, Clostridium difficile infection, irritable bowel syndrome, and chronic constipation as well as a variety of non-GI disorders. ${ }^{31,130}$ The transplants used in FMT could be either fresh stools or fecal frozen capsules, or extracts of bacterial flora from normal fecal flora. ${ }^{31}$ A recent study found that the FMT activated the tumor-associated $\mathrm{Wnt} / \beta$-catenin signaling pathway, but microbiota depletion by a cocktail of antibiotics was sufficient to block deoxycholic acid-induced intestinal carcinogenesis 
in mice. ${ }^{131}$ Despite the evidence being lacking at present for FMT in CRC treatment, fecal microbiota from patients with CRC is identified to directly promote intestinal carcinogenesis in germ-free mice and mice given a carcinogen. ${ }^{20}$ Thus, there is a reason to believe that FMT has a potential clinical effectiveness in the prevention and treatment of CRC by improving the balance and function of human IM.

It is notable that the impact of FMT on the recipient immune system is complicated and unpredictable, and the risk of dissemination of unknown pathogens through FMT cannot be eliminated. ${ }^{132}$ In addition, numerous outstanding questions remain, including FMT methodology - such as, what makes a "good donor," routes of administration, preparation of transplant material, regulatory frameworks, and long-term effects of FMT. ${ }^{31,133,134}$ If we can identify the favorable fecal microbiota composition or safe and functionally well-defined strains, and use prebiotics as the parcel material, FMT might be the low-burden alternative to chemo-/radiotherapy switch in the near future.

\section{The roles of IM in other treatments Surgery and chemo-/radiotherapy}

Incorporation of pro-/synbiotic formulations in the preoperative mechanical bowel preparation is insufficient to be supported by the present evidence. Limited clinical trials could be promising in supporting their potential role in reducing postoperative infection and tumor recurrence, and promoting quality of life after CRC resection. ${ }^{39,72}$ Chemo-/ radiotherapy has become the most common method for advanced CRC patients, but the GI side-effect is a serious problem that increases the patient's pain, and even endangers the patient's life. Microbial $\beta$-glucuronidases in the intestines can reactivate the excreted, inactive metabolite of irinotecan, a first-line chemotherapeutic for metastatic CRC, which causes adverse drug responses, including severe diarrhea. A recent study applied an approach to cancer chemotherapy through the use of a high-turnover microbiota metabotype with potentially elevated levels for microbial $\beta$-glucuronidases, which indicated that inhibiting these enzymes may decrease irinotecan-dependent adverse drug responses in targeted subsets of CRC patients. ${ }^{135}$ It is accepted that chemo-/radiotherapy-induced intestinal mucosal inflammation is closely related to the diversity of IM. ${ }^{136}$ Meanwhile, gut microbiota had been found to affect host's sensitivity to these therapies by modulating autophagy and metabolism. ${ }^{41,42,137,138}$ In addition, a mounting body of evidence had suggested that pro-/synbiotics could protect against chemo-/radiotherapy-induced diarrhea and mucosal inflammation. ${ }^{75-77}$ Interestingly, Singh et al $^{139}$ developed an improved oral delivery system that comprises three components, namely nanoparticles of drug coated with natural materials such as prebiotics, and probiotics, which plays a dual role of protecting the drug in the gastric as well as intestinal conditions to allow its release only in the colon. Deciphering microbiome-host interactions before and after chemo-/radiotherapy may eventually allow prediction of CRC course and offer opportunities for the discovery of specific gut bacteria or metabolites as bioengineered adjuvant for chemo-/radiotherapy.

\section{Immunotherapy}

Tumor immunotherapy, a novel biotherapeutic, could stimulate and mobilize host's immune system, and enhance anticancer immune response in tumor microenvironment, which eventually induces the apoptosis of carcinoma cells and inhibits tumor growth. However, the efficacy of immunotherapy has been a controversy in recent years. Negative regulation of tumor immune response is the most important reason to escape the antitumor immunotherapy mainly through recruiting or inducing inflammatory cells, including $\mathrm{T}$ regulatory cell (Treg), myeloid-derived suppressor cell (MDSC), and M2-like macrophage. ${ }^{140}$ In addition, the immune-checkpoint proteins cytotoxic $\mathrm{T}$ lymphocyte-associated antigen 4 (CTLA-4), programmed death-1 (PD-1), and programmed death receptor ligand-1 (PD-L1), and immunosuppressive cytokines of anticancer immune responses such as TGF- $\beta$, interleukin-10 (IL-10), IL-17, and IL-6, are also involved in the negative regulation of tumor immunity. ${ }^{141-144}$ Notably, several reports have shown that gut microbiota is of great accommodative value to anticancer immunotherapy responses. ${ }^{145-147}$

Treg cells could inhibit the function of CD4+ T cells, CD8+ T cells, dendritic cells (DC), and natural killer cells (NK), and promote the formation of immunosuppressive tumor microenvironment. ${ }^{148}$ A recent study had found that the amplification of Treg cells was closely associated with the IM, ETBF-triggered chronic inflammation and colon tumorigenesis in mice through the enhancement of Treg proliferation and IL-17 production. ${ }^{149}$ Importantly, cyclophosphamide (CTX) could induce the translocation of Gram-positive bacteria in the small intestine, provide "pathogenic" T helper 17 (pTh17) cells-based immune environment, and enhance the antitumor effect of CTX. ${ }^{150}$ Additionally, Enterococcus hirae translocated from the small intestine to secondary lymphoid organs and increased the intratumoral CD8+/Treg ratio, and Barnesiella intestinihominis 
accumulated in the colon and promoted the infiltration of interferon- $\gamma$-producing $\gamma \delta \mathrm{T}$ cells in cancer lesions, and in turn ameliorated the efficacy of anticancer immunomodulatory agent CTX. ${ }^{151}$ Moreover, CTX treatment decreased the proportion of Bacteroidetes while it increased the proportion of Firmicutes in the microbial community, and specific microbiota signatures belonging to Bacteroides and Alistipes respond to CTX therapy. ${ }^{152}$ Evidence of a pathogenic inflammatory signature in humans colonized with ETBF accelerated colorectal carcinogenesis, and promoted the differentiation of MDSCs, which selectively upregulated arginase- 1 and nitric oxide synthase-2, produced NO, and suppressed T-cell proliferation. ${ }^{153}$ Gram-negative strains such as Escherichia and Salmonella elevated inducible nitric oxide synthase expression, ${ }^{154}$ and B. fragilis ${ }^{155}$ also promoted the phagocytic functions of macrophages, polarizing them to an M1-like phenotype. IM imbalance can drive upregulation of IL-17C and B-cell lymphoma-2 in intestinal epithelial cells through TLR/MyD88-dependent signaling during intestinal tumorigenesis. ${ }^{156}$ These studies support the notion that depressing negative regulator-associated inflammatory cells and immunosuppressive cytokines through improving IM may be an attractive and promising strategy for antitumor immunotherapy (Figure 1).

Additional investigations had established that CD4+ CD25+ Treg cells could inhibit the immune function of activated T cells by upregulating the CTLA-4 expression, ${ }^{157}$ which combines $\mathrm{B} 7$ on the antigen-presenting cell, and then antagonizes the activation of CD28/B7 signaling and the antitumor immune response. ${ }^{158}$ Findings from animal tumor

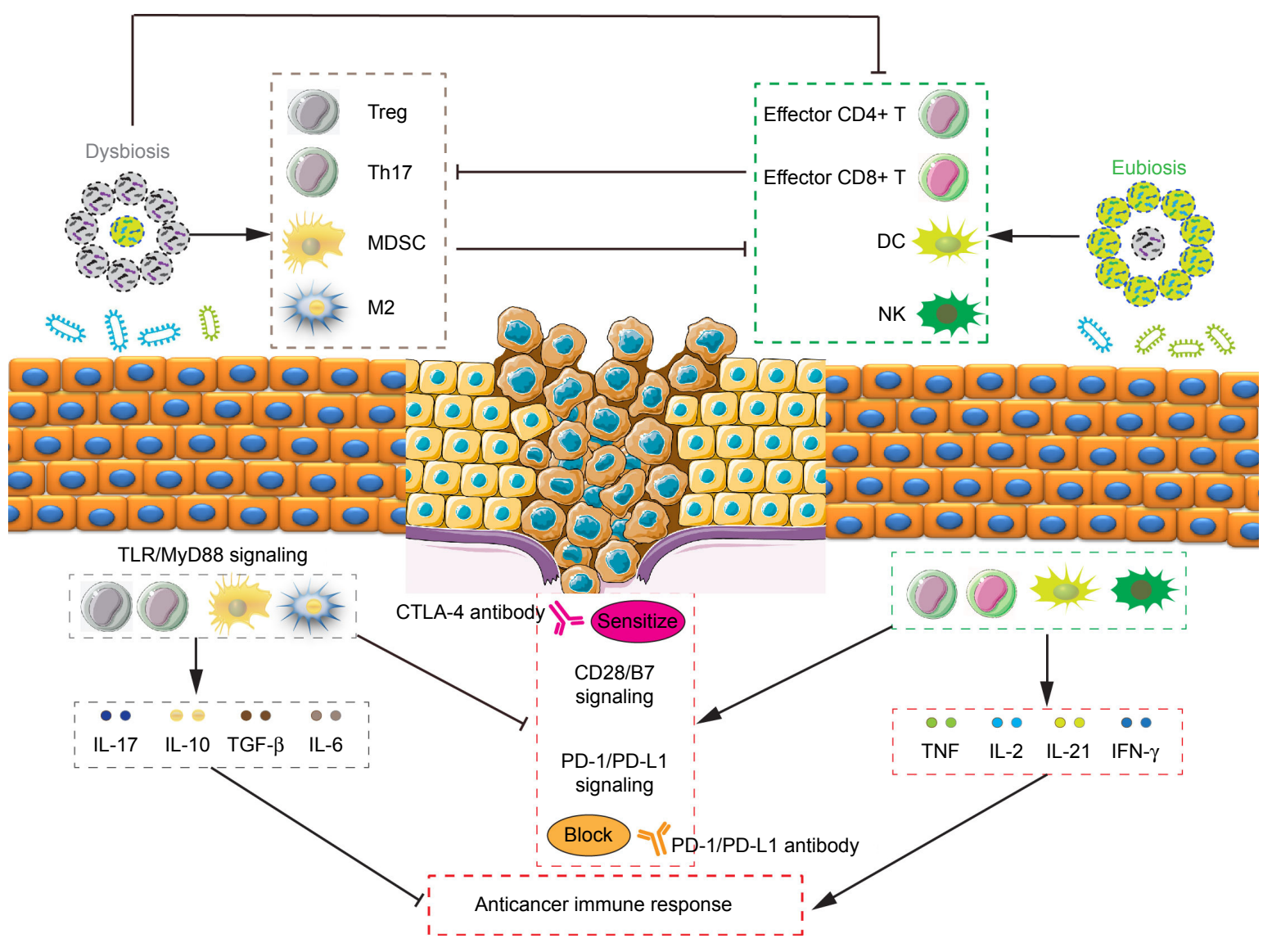

Figure I The roles of intestinal microbiota in the regulation of tumor immunity.

Notes: Inflammatory cells including Treg, ThI7, myeloid-derived suppressor cells, and M2 macrophage, immunosuppressive cytokines such as IL-I7, IL-10, TGF- $\beta$, and IL-6, and immune-checkpoint proteins CTLA-4 and PD-I/PD-LI are involved in the negative regulation of tumor immune response. It has shown that pathogenic bacteria (such as ETBF) or intestinal dysbacteriosis could drive amplification of inflammatory cells and upregulation of immunosuppressive cytokines through TLR-MyD88-dependent signaling. In addition, microbiota dysbiosis could inhibit the function of effector CD4+/CD8+ T cells, DC, and NK and promote the formation of immunosuppressive tumor microenvironment. By contrary, beneficial bacteria (such as Bacteroidales and Bifidobacterium) or microbiota eubiosis could favor the immune response of DC and T cells with anticancer properties through increasing the intratumoral effector CD4+/CD8+ proliferation and tumor necrosis factor, IL-2, IL-2I, and IFN- $\gamma$ production, which in turn inhibits the negative regulation of tumor immunity. Simultaneously holding immune-checkpoint antibody and probiotics could augment the function of DC and beneficial T cells, leading to enhanced CD8+ T-cell priming accumulation and sensitized CD28/B7 or blocked PD-I/PD-LI axis in the tumor microenvironment.

Abbreviations: CTLA-4, cytotoxic T lymphocyte-associated antigen 4; DC, dentritic cells; EBTF, enterotoxigenic Bacteroides fragilis; IL, interleukin; NK, natural killer cells; PD-I, programmed death-I; PD-LI, programmed death receptor ligand-I; TGF, tumor growth factor. 
Table 2 The effects and mechanisms of intestinal microbiota in anticancer immunotherapy

\begin{tabular}{|c|c|c|c|}
\hline Therapeutics & Regulation mechanism & Signatures & Reference \\
\hline \multirow[t]{4}{*}{ CTX } & Stimulated memory ThI immune responses, and provided "pathogenic" & Gram-positive bacteria & 150 \\
\hline & T helper 17 cells-based immune environment & & \\
\hline & Increased the intratumoral CD8+/Treg ratio, and promoted the infiltration & Enterococcus hirae and & $15 \mid$ \\
\hline & of IFN- $\gamma$-producing $\gamma \delta \mathrm{T}$ cells in cancer lesions & Barnesiella intestinihominis & \\
\hline \multirow[t]{4}{*}{ CTLA-4 antibody } & Favored the immune response of $\mathrm{DC}$ and $\mathrm{T}$ cells with anticancer & Bacteroidales & 36 \\
\hline & properties & & \\
\hline & Resisted to the development of checkpoint-blockade-induced colitis, & Bacteroidetes & 36,159 \\
\hline & reduced the risk of inflammatory complications & & \\
\hline \multirow[t]{6}{*}{ PD-I/PD-LI antibody } & Promoted the proliferation of beneficial T cells, and then inhibited the & Clostridiales bacteria & 160 \\
\hline & level of immunosuppressive cells & & \\
\hline & Augmented DC function leading to enhanced CD8+ T-cell priming & Bifidobacterium & 161 \\
\hline & accumulation in the tumor microenvironment & & \\
\hline & Increased the recruitment of CCR9+ CXCR3+CD4+ T cells into & Akkermansia muciniphila & 37 \\
\hline & tumor beds & & \\
\hline \multirow[t]{2}{*}{ CPG-ODN } & Induced the release of tumor necrosis factor leading to anti-tumor & Gram-negative Alistipes & 164 \\
\hline & immune response and tumor hemorrhagic necrosis through TRL4 signaling & genera & \\
\hline
\end{tabular}

Abbreviations: CCR9, CC chemokine receptor 9; CPG-ODN, CPG oligonucleotide; CTX, cyclophosphamide; CTLA-4, cytotoxic T-lymphocyte-associated antigen 4; CXCR3, C-X-C motif chemokine receptor 3; DC, dendritic cells; IFN, interferon; PD-I, programmed death I; PD-LI, programmed death receptor ligand I; TRL4, toll-like receptor 4.

models and human studies, and simultaneous holding of antiCTLA-4 antibody and Bacteroidales favored the immune response of DC and $\mathrm{T}$ cells with anticancer properties. ${ }^{36}$ In addition, it had shown that increased representation of Bacteroidetes was correlated with resistance to the development of CTLA-4 blockade-induced colitis. ${ }^{159}$ In addition to CTLA-4, another immune-checkpoint inhibitor, PD-1, could bind to tumor cell surface receptor PD-L1, sensitize PD-1/ PD-L1 signaling pathway, and promote tumor cells to escape immune surveillance and killing. ${ }^{141}$ A new study claimed that enriched Clostridiales bacteria was found in responders' gut microbiome undergoing anti-PD-1 immunotherapy in melanoma patients, and its underlying mechanism might be promoting the proliferation of beneficial $\mathrm{T}$ cells, and then inhibiting the level of immunosuppressive cells. ${ }^{160}$ Oral administration of Bifidobacterium and PD-L1-specific antibody could augment DC function leading to enhance CD8+ $\mathrm{T}$-cell priming accumulation in the tumor microenvironment, and then nearly abolish tumor outgrowth. ${ }^{161}$ Similar to these studies, Akkermansia muciniphila was identified to have a beneficial role in epithelial tumor patients who showed a good response to anti-PD-1 therapy, and oral supplementation with A. muciniphila post-FMT with nonresponder feces restored the efficacy of PD-1 blockade through increasing the recruitment of CCR9+ CXCR3+ CD4+ T cells into tumor beds. ${ }^{37}$ Additionally, more abundant bacterial species was observed to have greater clinical response to immunecheckpoint inhibitor therapy, which suggested that the commensal microbiome may have a mechanistic impact on antitumor immunity in human cancer patients. ${ }^{162,163}$ Besides these, commensal microbes combined with $\mathrm{CpG}$ oligonucleotide induced the release of TNF leading to antitumor immune response and tumor hemorrhagic necrosis through TRL4 signaling. ${ }^{164}$ To this end, we summarized the regulated roles of anticancer immunotherapy using IM (Table 2) and explored its underlying mechanism in the regulation of tumor immune response (Figure 1).

\section{Safety, deficiency, and future direction}

Although studies of IM have just begun, gut microbiotabased CRC therapy is a comparatively safe method with less side effects that is easily accepted by patients. Because of individual heredity, dietary preference, and life habit, the prevention and curative effects of IM-based CRC treatment may also vary from each other. How to formulate reasonable prescriptions for different groups and races to prevent generating new IM disorders or derangements, especially when using FMT? Another concern relates to the long-term efficacy, novel administration routes, and new formulations, which also require a systematic and scientific evaluation approach.

Moreover, several important scientific problems remain to be addressed, such as follows: 1) For now, the classification of IM mostly depends on 16S rRNA sequencing, which is a relatively rough method that can distinguish family and genus of bacteria, but usually not species and strains. Therefore, a huge difference in the percentage of single bacteria may be omitted. DNA microarray, ${ }^{122}$ matrix-assisted laser desorption ionization time-of-flight mass spectrometry, ${ }^{165} \mathrm{H}$-nuclear 
magnetic resonance spectroscopy, ${ }^{166}$ as well as other newer methods might help to study many complex bacterial ecosystems and constitute personalized medicine for CRC patients. 2) Current data suggest that the association between Helicobacter pylori and colorectal neoplasms may be population dependent, indicating that certain CRC subtypes may also be infectious diseases. ${ }^{167}$ The roles of gut microbiota in different CRC subtypes (including infection, inflammation, genetic mutations, and epigenetic modifications-associated CRC) are complex, and its maladjustment is the cause of tumorigenesis, or the result of tumor development is still uncertain. 3) Most studies on IM are based on animal models, especially the germ-free mice. Sterile mice are themselves a disease state; besides this, gut microbiota of humans and mice is also quite different, so using these animal studies to expand to clinical data needs to be carefully handled. 4) Despite that there are many clinical and preclinical tests about gut microbiota and CRC treatment, basically, a single or a few special bacterial communities are involved in these studies. The broad impact of commensal bacterial species on a wide range of health and/or CRC subjects will require consideration in settings of microorganism reconstitution with designer microbial syndicates, which is a commensal microbiome model including several gut strains. Notably, molecular pathologic epidemiology can enhance causal inference by linking putative etiology, and contribute to biomarker research and precision medicine. It can be used for research on dietary and environmental factors, microbiome, various omics, in combination with CRC phenotype including microbial profiling in tissues. ${ }^{168,169}$

According to the data obtained over the past few years, it is plausible that gut microbiome could be used as an early diagnostic biomarker of CRC by using fecal proteomics and microbiota-based prediction, monitoring IM profile. ${ }^{165,170-172}$ In addition, checking specific biomarker of IM in urine has been predicted to reduce intestinal graft-versus-host disease and treatment-related mortality. ${ }^{173}$ Gastric microbial composition can be used to distinguish chronic gastritis and gastric carcinoma. ${ }^{32}$ There is a reason to believe that CRC might be diagnosed in near future only through detecting characteristic markers of microbiota in feces, urine, or blood. Recent studies revealed that genetically modified bacteria as a tool to detect microscopic solid tumor masses even could effectively colonize solid tumors and act as antitumor therapeutics, suggesting that genetically manipulated bacteria has great potential in CRC treatment/prevention in the future. ${ }^{174,175}$ Given the immunomodulatory effects and modern theories, gut microbiota can also be used to research CRC vaccines or adjuvant, which is applied for the maintainment of intestinal normal barrier and immune response. Moreover, IM might be used to monitor the sensitivity and outcomes of chemo-/radiotherapy and immunotherapy in CRC patients based on the recent studies in mice models. Besides these, immunotherapies or chemoimmunotherapies might also have variable reliance on gut microbiota for T-cell activation and function, and thus have a potential as novel strategies in individualized treatment.

\section{Conclusion}

Despite that there are still lots of deficiencies and problems associated with utilizing IM in CRC treatment, IM-based CRC therapy is well tolerant, comparatively safe, and of a comfortable pattern. Combined application of gut microbiota and other therapeutics, especially immunotherapy, shows a powerful synergistic efficiency to treat CRC settings or restrain side effect. Systematic and credible preclinical and clinical studies will help to get a good understanding of molecular mechanism, which could further expand the application of IM in the early diagnosis and prevention of CRC. We believe that it offers opportunities for the development of novel therapeutic or prophylactic strategies.

\section{Acknowledgments}

This work was supported in part by grants from the Postgraduate Research \& Practice Innovation Program of Jiangsu Province (KYCX17_0179), the Scientific Research Foundation of Graduate School of Southeast University (YBJJ1798), the National Science and Technology Major Project of China (No 2018Z × 09301026-005), the National Natural Science Foundation of China (81773624), and the Project of Social Development of Jiangsu Province (BE2017746).

\section{Author contributions}

Chenbo Ding conceived and designed the conception of the manuscript. Wendong Tang, Xiaobo Fan, and Guoqiu Wu contributed to literature search. Guoqiu Wu participated in the conception and coordination. All authors contributed toward data analysis, and drafting and revising the paper and agreed to be accountable for all aspects of the work.

\section{Disclosure}

The authors report no conflicts of interest in this work.

\section{References}

1. Torre LA, Bray F, Siegel RL, Ferlay J, Lortet-Tieulent J, Jemal A. Global cancer statistics, 2012. CA Cancer J Clin. 2015;65(2):87-108. 
2. Chen W, Zheng R, Baade PD, et al. Cancer statistics in China, 2015. CA Cancer J Clin. 2016;66(2):115-132.

3. Fearon ER. Molecular genetics of colorectal cancer. Annu Rev Pathol. 2011;6(1):479-507.

4. Jafri SH, Mills G. Lifestyle modification in colorectal cancer patients: an integrative oncology approach. Future Oncol. 2013;9(2):207-218.

5. Okugawa Y, Grady WM, Goel A. Epigenetic alterations in colorectal cancer: emerging biomarkers. Gastroenterology. 2015;149(5): 1204-1225.

6. Lasry A, Zinger A, Ben-Neriah Y. Inflammatory networks underlying colorectal cancer. Nat Immunol. 2016;17(3):230-240.

7. O'Keefe SJ. Diet, microorganisms and their metabolites, and colon cancer. Nat Rev Gastroenterol Hepatol. 2016;13(12):691-706.

8. Jess T, Simonsen J, Jørgensen KT, Pedersen BV, Nielsen NM, Frisch M. Decreasing risk of colorectal cancer in patients with inflammatory bowel disease over 30 years. Gastroenterology. 2012;143(2): $375-381$.

9. Jess T, Horváth-Puhó E, Fallingborg J, Rasmussen HH, Jacobsen BA. Cancer risk in inflammatory bowel disease according to patient phenotype and treatment: a Danish population-based cohort study. Am J Gastroenterol. 2013;108(12):1869-1876.

10. Johnson CM, Wei C, Ensor JE, et al. Meta-analyses of colorectal cancer risk factors. Cancer Causes Control. 2013;24(6):1207-1222.

11. Farraye FA, Odze RD, Eaden J, Itzkowitz SH. AGA medical position statement on the diagnosis and management of colorectal neoplasia in inflammatory bowel disease. Gastroenterology. 2010;138(2):738-745.

12. Kostic AD, Chun E, Meyerson M, Garrett WS. Microbes and inflammation in colorectal cancer. Cancer Immunol Res. 2013;1(3):150-157.

13. Bruner SD, Jobin C. Intestinal microbiota in inflammatory bowel disease and carcinogenesis: implication for therapeutics. Clin Pharmacol Ther. 2016;99(6):585-587.

14. Ijssennagger N, van der Meer R, van Mil SWC. Sulfide as a mucus barrier-breaker in inflammatory bowel disease? Trends Mol Med. 2016; 22(3):190-199.

15. Hooper LV, Gordon JI. Commensal host-bacterial relationships in the gut. Science. 2001;292(5519):1115-1118.

16. Reinoso Webb C, den Bakker H, Koboziev I, et al. Differential susceptibility to $\mathrm{T}$ cell-induced colitis in mice: role of the intestinal microbiota. Inflamm Bowel Dis. 2018;24(2):361-379.

17. Uronis JM, Mühlbauer M, Herfarth HH, Rubinas TC, Jones GS, Jobin C. Modulation of the intestinal microbiota alters colitis-associated colorectal cancer susceptibility. PLoS One. 2009;4(6):e6026.

18. Li Y, Kundu P, Seow SW, et al. Gut microbiota accelerate tumor growth via c-jun and STAT3 phosphorylation in APC Min/+ mice. Carcinogenesis. 2012;33(6):1231-1238.

19. Yu J, Feng Q, Wong SH, et al. Metagenomic analysis of faecal microbiome as a tool towards targeted non-invasive biomarkers for colorectal cancer. Gut. 2017;66(1):70-78.

20. Wong SH, Zhao L, Zhang X, et al. Gavage of fecal samples from patients with colorectal cancer promotes intestinal carcinogenesis in germ-free and conventional mice. Gastroenterology. 2017;153(6):1621-1633.

21. Dejea CM, Fathi P, Craig JM, et al. Patients with familial adenomatous polyposis harbor colonic biofilms containing tumorigenic bacteria. Science. 2018;359(6375):592-597.

22. Rowland I. The role of the gastrointestinal microbiota in colorectal cancer. Curr Pharm Des. 2009;15(13):1524-1527.

23. Wang X, Allen TD, May RJ, Lightfoot S, Houchen CW, Huycke MM. Enterococcus faecalis induces aneuploidy and tetraploidy in colonic epithelial cells through a bystander effect. Cancer Res. 2008;68(23): 9909-9917.

24. Singh N, Gurav A, Sivaprakasam S, et al. Activation of Gpr109a, receptor for niacin and the commensal metabolite butyrate, suppresses colonic inflammation and carcinogenesis. Immunity. 2014;40(1):128-139.

25. Sears CL, Pardoll DM. Perspective: alpha-bugs, their microbial partners, and the link to colon cancer. J Infect Dis. 2011;203(3):306-311.

26. Tjalsma H, Boleij A, Marchesi JR, Dutilh BE. A bacterial driverpassenger model for colorectal cancer: beyond the usual suspects. Nat Rev Microbiol. 2012;10(8):575-582.
27. Gallimore AM, Godkin A. Epithelial barriers, microbiota, and colorectal cancer. N Engl J Med Overseas Ed. 2013;368(3):282-284.

28. Ahmed S, Johnson K, Ahmed O, Iqbal N. Advances in the management of colorectal cancer: from biology to treatment. Int J Colorectal Dis. 2014;29(9):1031-1042.

29. Field K, Lipton L. Metastatic colorectal cancer-past, progress and future. World J Gastroenterol. 2007;13(28):3806-3815.

30. Duranti S, Gaiani F, Mancabelli L, et al. Elucidating the gut microbiome of ulcerative colitis: bifidobacteria as novel microbial biomarkers. FEMS Microbiol Ecol. 2016;92(12):fiw191.

31. Smits LP, Bouter KEC, de Vos WM, Borody TJ, Nieuwdorp M. Therapeutic potential of fecal microbiota transplantation. Gastroenterology. 2013;145(5):946-953.

32. Ferreira RM, Pereira-Marques J, Pinto-Ribeiro I, et al. Gastric microbial community profiling reveals a dysbiotic cancer-associated microbiota. Gut. 2018;67(2):226-236.

33. Lenoir M, del Carmen S, Cortes-Perez NG, et al. Lactobacillus casei BL23 regulates Treg and Th17 T-cell populations and reduces DMH-associated colorectal cancer. $J$ Gastroenterol. 2016;51(9): 862-873.

34. Wijnands MVW, Schoterman HC, Bruijntjes JB, Hollanders VM, Woutersen RA. Effect of dietary galacto-oligosaccharides on azoxymethane-induced aberrant crypt foci and colorectal cancer in Fischer 344 rats. Carcinogenesis. 2001;22(1):127-132.

35. Zackular JP, Baxter NT, Iverson KD, et al. The gut microbiome modulates colon tumorigenesis. MBio. 2013;4(6):e00692-13.

36. Vétizou M, Pitt JM, Daillère R, et al. Anticancer immunotherapy by CTLA-4 blockade relies on the gut microbiota. Science. 2015; 350(6264):1079-1084.

37. Routy B, Le Chatelier E, Derosa L, et al. Gut microbiome influences efficacy of PD-1-based immunotherapy against epithelial tumors. Science. 2018;359(6371):91-97.

38. Roller M, Clune Y, Collins K, Rechkemmer G, Watzl B. Consumption of prebiotic inulin enriched with oligofructose in combination with the probiotics Lactobacillus rhamnosus and Bifidobacterium lactis has minor effects on selected immune parameters in polypectomised and colon cancer patients. Br J Nutr. 2007;97(04):676-684.

39. Ohigashi S, Hoshino Y, Ohde S, Onodera H. Functional outcome, quality of life, and efficacy of probiotics in postoperative patients with colorectal cancer. Surg Today. 2011;41(9):1200-1206.

40. Rafter J, Bennett M, Caderni G, et al. Dietary synbiotics reduce cancer risk factors in polypectomized and colon cancer patients. Am J Clin Nutr. 2007;85(2):488-496.

41. Crawford PA, Gordon JI. From the cover: microbial regulation of intestinal radiosensitivity. Proc Natl Acad Sci. 2005;102(37): 13254-13259

42. Yu T, Guo F, Yu Y, et al. Fusobacterium nucleatum promotes chemoresistance to colorectal cancer by modulating autophagy. Cell. 2017; 170(3):548-563.

43. Dejea CM, Wick EC, Hechenbleikner EM, et al. Microbiota organization is a distinct feature of proximal colorectal cancers. Proc Natl Acad Sci. 2014;111(51):18321-18326.

44. Li S, Konstantinov SR, Smits R, Peppelenbosch MP. Bacterial biofilms in colorectal cancer initiation and progression. Trends Mol Med. 2017; 23(1):18-30.

45. Sicard J-F, Le Bihan G, Vogeleer P, Jacques M, Harel J. Interactions of intestinal bacteria with components of the intestinal mucus. Front Cell Infect Microbiol. 2017;7:387.

46. Nakatsu G, Li X, Zhou H, et al. Gut mucosal microbiome across stages of colorectal carcinogenesis. Nat Commun. 2015;6(1):8727.

47. Huipeng W, Lifeng G, Chuang G, Jiaying Z, Yuankun C. The differences in colonic mucosal microbiota between normal individual and colon cancer patients by polymerase chain reaction-denaturing gradient gel electrophoresis. J Clin Gastroenterol. 2014;48(2):138-144.

48. Warren RL, Freeman DJ, Pleasance S, et al. Co-occurrence of anaerobic bacteria in colorectal carcinomas. Microbiome. 2013;1(1):16.

49. Wu N, Yang X, Zhang R, et al. Dysbiosis signature of fecal microbiota in colorectal cancer patients. Microb Ecol. 2013;66(2):462-470. 
50. Kahouli I, Tomaro-Duchesneau C, Prakash S. Probiotics in colorectal cancer (CRC) with emphasis on mechanisms of action and current perspectives. J Med Microbiol. 2013;62(Pt_8):1107-1123.

51. Ito M, Kanno S, Nosho K, et al. Association of Fusobacterium nucleatum with clinical and molecular features in colorectal serrated pathway. Int J Cancer. 2015;137(6):1258-1268.

52. Park CH, Han DS, Oh Y-H, Lee A-Reum, Lee Y-Ra, Eun CS. Role of Fusobacteria in the serrated pathway of colorectal carcinogenesis. Sci Rep. 2016;6(1):25271.

53. Yang Y, Weng W, Peng J, et al. Fusobacterium nucleatum increases proliferation of colorectal cancer cells and tumor development in mice by activating toll-like receptor 4 signaling to nuclear factor $-\kappa \mathrm{B}$, and up-regulating expression of microRNA-21. Gastroenterology. 2017; 152(4):851-866.

54. Ye X, Wang R, Bhattacharya R, et al. Fusobacterium nucleatum subspecies Animalis influences proinflammatory cytokine expression and monocyte activation in human colorectal tumors. Cancer Prev Res. 2017;10(7):398-409.

55. Nosho K, Sukawa Y, Adachi Y, et al. Association of Fusobacterium nucleatum with immunity and molecular alterations in colorectal cancer. World J Gastroenterol. 2016;22(2):557-566.

56. Pandey KR, Naik SR, Vakil BV. Probiotics, prebiotics and synbiotics-a review. J Food Sci Technol. 2015;52(12):7577-7587.

57. Zhang M, Sun K, Wu Y, Yang Y, Tso P, Wu Z. Interactions between intestinal microbiota and host immune response in inflammatory bowel disease. Front Immunol. 2017;8:942.

58. Escamilla J, Lane MA, Maitin V. Cell-free supernatants from probiotic Lactobacillus casei and Lactobacillus rhamnosus GG decrease colon cancer cell invasion in vitro. Nutr Cancer. 2012;64(6): $871-878$

59. Orlando A, Refolo MG, Messa C, et al. Antiproliferative and proapoptotic effects of viable or heat-killed Lactobacillus paracasei IMPC2.1 and Lactobacillus rhamnosus GG in HGC-27 gastric and DLD-1 colon cell lines. Nutr Cancer. 2012;64(7):1103-1111.

60. Chen Z-Y, Hsieh Y-M, Huang C-C, Tsai C-C. Inhibitory effects of probiotic Lactobacillus on the growth of human colonic carcinoma cell line HT-29. Molecules. 2017;22(1):107.

61. Cousin FJ, Jouan-Lanhouet S, Théret N, et al. The probiotic Propionibacterium freudenreichii as a new adjuvant for TRAIL-based therapy in colorectal cancer. Oncotarget. 2016;7(6):7161-7178.

62. del Carmen S, de Moreno de Leblanc A, Levit R, et al. Anti-cancer effect of lactic acid bacteria expressing antioxidant enzymes or IL-10 in a colorectal cancer mouse model. Int Immunopharmacol. 2017;42: $122-129$.

63. Park E, Jeon G-I, Park J-S, Paik H-D. A probiotic strain of Bacillus polyfermenticus reduces DMH induced precancerous lesions in F344 male rat. Biol Pharm Bull. 2007;30(3):569-574.

64. Lee N-K, Park J-S, Park E, Paik H-D. Adherence and anticarcinogenic effects of Bacillus polyfermenticus SCD in the large intestine. Lett Appl Microbiol. 2007;44(3):274-278.

65. Kumar RS, Kanmani P, Yuvaraj N, et al. Lactobacillus plantarum AS1 isolated from South Indian fermented food kallappam suppress 1,2dimethyl hydrazine (DMH)-induced colorectal cancer in male Wistar rats. Appl Biochem Biotechnol. 2012;166(3):620-631.

66. Asha Gayathri D. Synergistic impact of Lactobacillus fermentum, Lactobacillus plantarum and vincristine on 1,2-dimethylhydrazineinduced colorectal carcinogenesis in mice. Exp Ther Med. 2012;3(6): 1049-1054.

67. Mohania D, Kansal VK, Kruzliak P, Kumari A. Probiotic dahi containing Lactobacillus acidophilus and Bifidobacterium bifidum modulates the formation of aberrant crypt foci, mucin-depleted foci, and cell proliferation on 1,2-dimethylhydrazine-induced colorectal carcinogenesis in Wistar rats. Rejuvenation Res. 2014;17(4): 325-333.

68. Urbanska AM, Bhathena J, Martoni C, Prakash S. Estimation of the potential antitumor activity of microencapsulated Lactobacillus acidophilus yogurt formulation in the attenuation of tumorigenesis in Apc(Min/+) mice. Dig Dis Sci. 2009;54(2):264-273.
69. Chen X, Fruehauf J, Goldsmith JD, et al. Saccharomyces boulardii inhibits EGF receptor signaling and intestinal tumor growth in Apcmin mice. Gastroenterology. 2009;137(3):914-923.

70. Ho CL, Tan HQ, Chua KJ, et al. Engineered commensal microbes for diet-mediated colorectal-cancer chemoprevention. Nat Biomed Eng. 2018;2:27-37.

71. Gianotti L, Morelli L, Galbiati F, et al. A randomized double-blind trial on perioperative administration of probiotics in colorectal cancer patients. World J Gastroenterol. 2010;16(2):167-175.

72. Liu D, Jiang XY, Zhou LS, Song JH, Zhang X. Effects of probiotics on intestinal mucosa barrier in patients with colorectal cancer after operation: meta-analysis of randomized controlled trials. Medicine. 2016; 95(15):e3342.

73. Pala V, Sieri S, Berrino F, et al. Yogurt consumption and risk of colorectal cancer in the Italian European prospective investigation into cancer and nutrition cohort. Int J Cancer. 2011;129(11):2712-2719.

74. Ishikawa H, Akedo I, Otani $\mathrm{T}$, et al. Randomized trial of dietary fiber and Lactobacillus casei administration for prevention of colorectal tumors. Int J Cancer. 2005;116(5):762-767.

75. Österlund P, Ruotsalainen T, Korpela R, et al. Lactobacillus supplementation for diarrhoea related to chemotherapy of colorectal cancer: a randomised study. Br J Cancer. 2007;97(8):1028-1034.

76. Delia P, Sansotta G, Donato V, et al. Use of probiotics for prevention of radiation-induced diarrhea. World J Gastroenterol. 2007;13(6): 912-915.

77. Timko J. Probiotics as prevention of radiation-induced diarrhoea. J Radiother Pract. 2010;9(04):201-208.

78. Zhang JW, du P, Gao J, Yang BR, Fang WJ, Ying CM. Preoperative probiotics decrease postoperative infectious complications of colorectal cancer. Am J Med Sci. 2012;343(3):199-205.

79. Zhang JW, du P, Chen DW, Cui L, Ying CM. Effect of viable Bifidobacterium supplement on the immune status and inflammatory response in patients undergoing resection for colorectal cancer. Zhonghua Wei Chang Wai Ke Za Zhi. 2010;13(1):Chinese:40-43.

80. Xia Y, Yang Z, Chen HQ, Qin HL. Effect of bowel preparation with probiotics on intestinal barrier after surgery for colorectal cancer. Zhonghua Wei Chang Wai Ke Za Zhi. 2010;13(7):Chinese:528-531.

81. Theodoropoulos GE, Memos NA, Peitsidou K, Karantanos T, Spyropoulos BG, Zografos G. Synbiotics and gastrointestinal functionrelated quality of life after elective colorectal cancer resection. Ann Gastroenterol. 2016;29(1):56-62.

82. Liu Z, Qin H, Yang Z, et al. Randomised clinical trial: the effects of perioperative probiotic treatment on barrier function and post-operative infectious complications in colorectal cancer surgery - a double-blind study. Aliment Pharmacol Ther. 2011;33(1):50-63.

83. Liu Z-H, Huang M-J, Zhang X-W, et al. The effects of perioperative probiotic treatment on serum zonulin concentration and subsequent postoperative infectious complications after colorectal cancer surgery: a double-center and double-blind randomized clinical trial. Am J Clin Nutr. 2013;97(1):117-126.

84. Zhu D, Chen X, Wu J, et al. Effect of perioperative intestinal probiotics on intestinal flora and immune function in patients with colorectal cancer. Nan Fang Yi Ke Da Xue Xue Bao. 2012;32(8):Chinese:1190-1193.

85. Kotzampassi K, Stavrou G, Damoraki G, Georgitsi M, Basdanis G, Tsaousi G, Giamarellos-Bourboulis EJ. A four-probiotics regimen reduces postoperative complications after colorectal surgery: a randomized, double-blind, placebo-controlled study. World J Surg. 2015; 39(11):2776-2783.

86. Yang Y, Xia Y, Chen H, et al. The effect of perioperative probiotics treatment for colorectal cancer: short-term outcomes of a randomized controlled trial. Oncotarget. 2016;7(7):8432-8440.

87. Horvat M, Krebs B, Potrč S, Ivanecz A, Kompan L. Preoperative synbiotic bowel conditioning for elective colorectal surgery. Wien Klin Wochenschr. 2010;122(S2):26-30.

88. Reddy BS, Macfie J, Gatt M, Larsen CN, Jensen SS, Leser TD. Randomized clinical trial of effect of synbiotics, neomycin and mechanical bowel preparation on intestinal barrier function in patients undergoing colectomy. Br J Surg. 2007;94(5):546-554. 
89. de Oliveira AL, Aarestrup FM. Nutritional status and systemic inflammatory activity of colorectal patients on symbiotic supplementation. Arq Bras Cir Dig. 2012;25(3):147-153.

90. Liu Z, Li C, Huang M, et al. Positive regulatory effects of perioperative probiotic treatment on postoperative liver complications after colorectal liver metastases surgery: a double-center and double-blind randomized clinical trial. BMC Gastroenterol. 2015;15(1):34.

91. Mego M, Májek J, Končeková R, et al. Intramucosal bacteria in colon cancer and their elimination by probiotic strain Enterococcus faecium M-74 with organic selenium. Folia Microbiol. 2005;50(5):443-447.

92. Liang S, Xu L, Zhang D, Wu Z. Effect of probiotics on small intestinal bacterial overgrowth in patients with gastric and colorectal cancer. Turk J Gastroenterol. 2016;27(3):227-232.

93. Lee J-Y, Chu S-H, Jeon JY, et al. Effects of 12 weeks of probiotic supplementation on quality of life in colorectal cancer survivors: a doubleblind, randomized, placebo-controlled trial. Dig Liver Dis. 2014; 46(12):1126-1132.

94. Krebs B. Prebiotic and synbiotic treatment before colorectal surgeryrandomised double blind trial. Coll Antropol. 2016;40(1):35-40.

95. Mcnaught CE, Woodcock NP, Macfie J, Mitchell CJ. A prospective randomised study of the probiotic Lactobacillus plantarum $299 \mathrm{~V}$ on indices of gut barrier function in elective surgical patients. Gut. 2002; 51(6):827-831.

96. Anderson ADG, Mcnaught CE, Jain PK, Macfie J. Randomised clinical trial of synbiotic therapy in elective surgical patients. Gut. 2004; 53(2):241-245.

97. Krebs B, Horvat M, Golle A, et al. A randomized clinical trial of synbiotic treatment before colorectal cancer surgery. Am Surg. 2013; 79(12):E340-E342.

98. Worthley DL, Le Leu RK, Whitehall VL, et al. A human, doubleblind, placebo-controlled, crossover trial of prebiotic, probiotic, and synbiotic supplementation: effects on luminal, inflammatory, epigenetic, and epithelial biomarkers of colorectal cancer. Am J Clin Nutr. 2009;90(3):578-586.

99. Gibson GR, Hutkins R, Sanders ME, et al. Expert consensus document: The International Scientific Association for Probiotics and Prebiotics (ISAPP) consensus statement on the definition and scope of prebiotics. Nat Rev Gastroenterol Hepatol. 2017;14(8):491-502.

100. Sun H, Chen Y, Cheng M, Zhang X, Zheng X, Zhang Z. The modulatory effect of polyphenols from green tea, oolong tea and black tea on human intestinal microbiota in vitro. J Food Sci Technol. 2018; 55(1):399-407.

101. Allsopp P, Possemiers S, Campbell D, Oyarzábal IS, Gill C, Rowland I. An exploratory study into the putative prebiotic activity of fructans isolated from Agave angustifolia and the associated anticancer activity. Anaerobe. 2013;22:38-44.

102. Lee SM, Chang JY, Wu JS, Sheu DC. Antineoplastic effect of a novel chemopreventive agent, neokestose, on the Caco- 2 cell line via inhibition of expression of nuclear factor- $\kappa \mathrm{B}$ and cyclooxygenase-2. Mol Med Rep. 2015;12(1):1114-1118.

103. Fukuda M, Komiyama Y, Mitsuyama K, et al. Prebiotic treatment reduced preneoplastic lesions through the downregulation of toll like receptor 4 in a chemo-induced carcinogenic model. J Clin Biochem Nutr. 2011;49(1):57-61.

104. Qamar TR, Syed F, Nasir M, et al. Novel combination of prebiotics galacto-oligosaccharides and inulin-inhibited aberrant crypt foci formation and biomarkers of colon cancer in Wistar rats. Nutrients. 2016;8(8):E465

105. Eid N, Osmanova H, Natchez C, et al. Impact of palm date consumption on microbiota growth and large intestinal health: a randomised, controlled, cross-over, human intervention study. Br J Nutr. 2015; 114(8):1226-1236.

106. Le Leu RK, Winter JM, Christophersen CT, et al. Butyrylated starch intake can prevent red meat-induced O6-methyl-2-deoxyguanosine adducts in human rectal tissue: a randomised clinical trial. Br J Nutr. 2015;114(2):220-230.
107. Molan AL, Liu Z, Plimmer G. Evaluation of the effect of blackcurrant products on gut microbiota and on markers of risk for colon cancer in humans. Phytother Res. 2014;28(3):416-422.

108. Windey K, de Preter V, Huys G, et al. Wheat bran extract alters colonic fermentation and microbial composition, but does not affect faecal water toxicity: a randomised controlled trial in healthy subjects. $\mathrm{Br} J$ Nutr. 2015;113(2):225-238.

109. Mehta RS, Nishihara R, Cao Y, et al. Association of dietary patterns with risk of colorectal cancer subtypes classified by fusobacterium nucleatum in tumor tissue. JAMA Oncol. 2017;3(7):921-927.

110. Limburg PJ, Mahoney MR, Ziegler KL, et al. Randomized phase II trial of sulindac, atorvastatin, and prebiotic dietary fiber for colorectal cancer chemoprevention. Cancer Prev Res. 2011;4(2):259-269.

111. Bubici C, Papa S. JNK signalling in cancer: in need of new, smarter therapeutic targets. Br J Pharmacol. 2014;171(1):24-37.

112. Gupta J, Nebreda AR. Roles of p $38 \alpha$ mitogen-activated protein kinase in mouse models of inflammatory diseases and cancer. FEBS J. 2015;282(10):1841-1857.

113. Bentley-Hewitt KL, de Guzman CE, Ansell J, Mandimika T, Narbad A, Lund EK. Polyunsaturated fatty acids modify expression of TGF- $\beta$ in a co-culture model ultilising human colorectal cells and human peripheral blood mononuclear cells exposed to Lactobacillus gasseri, Escherichia coli and Staphylococcus aureus. Eur J Lipid Sci Technol. 2014;116(5):505-513.

114. Cao Y, Wu K, Mehta R, et al. Long-term use of antibiotics and risk of colorectal adenoma. Gut. 2018;67(4):672-678.

115. Ijssennagger N, Belzer C, Hooiveld GJ, et al. Gut microbiota facilitates dietary heme-induced epithelial hyperproliferation by opening the mucus barrier in colon. Proc Natl Acad Sci US A. 2015;112(32): 10038-10043.

116. Martin OC, Lin C, Naud N, et al. Antibiotic suppression of intestinal microbiota reduces heme-induced lipoperoxidation associated with colon carcinogenesis in rats. Nutr Cancer. 2015;67(1): 119-125.

117. Ushijima H, Horyozaki A, Maeda M. Anisomycin-induced GATA-6 degradation accompanying a decrease of proliferation of colorectal cancer cell. Biochem Biophys Res Commun. 2016;478(1):481-485.

118. Prabhu VV, Hong B, Allen JE, et al. Small-molecule prodigiosin restores p53 tumor suppressor activity in chemoresistant colorectal cancer stem cells via c-Jun-mediated $\Delta \mathrm{Np} 73$ inhibition and $\mathrm{p} 73$ activation. Cancer Res. 2016;76(7):1989-1999.

119. Klose J, Eissele J, Volz C, et al. Salinomycin inhibits metastatic colorectal cancer growth and interferes with Wnt/ $\beta$-catenin signaling in $\mathrm{CD}_{133^{+}}$human colorectal cancer cells. BMC Cancer. 2016;16(1):896.

120. Hamoya T, Miyamoto S, Tomono S, et al. Chemopreventive effects of a low-side-effect antibiotic drug, erythromycin, on mouse intestinal tumors. J Clin Biochem Nutr. 2017;60(3):199-207.

121. Bullman S, Pedamallu CS, Sicinska E, et al. Analysis of Fusobacterium persistence and antibiotic response in colorectal cancer. Science. 2017;358(6369):1443-1448.

122. Tomasello G, Mazzola M, Jurjus A, et al. The fingerprint of the human gastrointestinal tract microbiota: a hypothesis of molecular mapping. J Biol Regul Homeost Agents. 2017;31(1):245-249.

123. Elrakaiby M, Dutilh BE, Rizkallah MR, Boleij A, Cole JN, Aziz RK. Pharmacomicrobiomics: the impact of human microbiome variations on systems pharmacology and personalized therapeutics. OMICS. 2014;18(7):402-414.

124. Montrose DC, Zhou XK, Mcnally EM, et al. Celecoxib alters the intestinal microbiota and metabolome in association with reducing polyp burden. Cancer Prev Res. 2016;9(9):721-731.

125. Yu YN, Yu TC, Zhao HJ, et al. Berberine may rescue Fusobacterium nucleatum-induced colorectal tumorigenesis by modulating the tumor microenvironment. Oncotarget. 2015;6(31):32013-32026.

126. Wu M, Wu Y, Deng B, et al. Isoliquiritigenin decreases the incidence of colitis-associated colorectal cancer by modulating the intestinal microbiota. Oncotarget. 2016;7(51):85318-85331. 
127. Mcfadden RM, Larmonier CB, Shehab KW, et al. The role of curcumin in modulating colonic microbiota during colitis and colon cancer prevention. Inflamm Bowel Dis. 2015;21(11):2483-2494.

128. Wang CZ, Calway T, Yuan CS. Herbal medicines as adjuvants for cancer therapeutics. Am J Chin Med. 2012;40(4):657-669.

129. Eiseman B, Silen W, Bascom GS, Kauvar AJ. Fecal enema as an adjunct in the treatment of pseudomembranous enterocolitis. Surgery. 1958;44(5):854-859.

130. Borody TJ, Khoruts A. Fecal microbiota transplantation and emerging applications. Nat Rev Gastroenterol Hepatol. 2011;9(2):88-96.

131. Cao H, Xu M, Dong W, et al. Secondary bile acid-induced dysbiosis promotes intestinal carcinogenesis. Int J Cancer. 2017;140(11): 2545-2556.

132. Pamer EG. Fecal microbiota transplantation: effectiveness, complexities, and lingering concerns. Mucosal Immunol. 2014;7(2):210-214.

133. Borody TJ, Paramsothy S, Agrawal G. Fecal microbiota transplantation: indications, methods, evidence, and future directions. Curr Gastroenterol Rep. 2013;15(8):337.

134. Hoffmann D, Palumbo F, Ravel J, Roghmann MC, Rowthorn V, von Rosenvinge E. Improving regulation of microbiota transplants. Science. 2017;358(6369):1390-1391.

135. Guthrie L, Gupta S, Daily J, Kelly L. Human microbiome signatures of differential colorectal cancer drug metabolism. NPJ Biofilms Microbiomes. 2017;3:27.

136. Touchefeu Y, Montassier E, Nieman K, et al. Systematic review: the role of the gut microbiota in chemotherapy- or radiation-induced gastrointestinal mucositis - current evidence and potential clinical applications. Aliment Pharmacol Ther. 2014;40(5):409-421.

137. Scott TA, Quintaneiro LM, Norvaisas P, et al. Host-microbe cometabolism dictates cancer drug efficacy in C. elegans. Cell. 2017; 169(3):442-456.

138. Packey CD, Ciorba MA. Microbial influences on the small intestinal response to radiation injury. Curr Opin Gastroenterol. 2010;26(2): 88-94.

139. Singh S, Kotla NG, Tomar S, et al. A nanomedicine-promising approach to provide an appropriate colon-targeted drug delivery system for 5-fluorouracil. Int J Nanomedicine. 2015;10:7175-7182.

140. de Vries NL, Swets M, Vahrmeijer AL, Hokland M, Kuppen PJ. The immunogenicity of colorectal cancer in relation to tumor development and treatment. Int J Mol Sci. 2016;17(7):E1030.

141. Nishino M, Ramaiya NH, Hatabu H, Hodi FS. Monitoring immunecheckpoint blockade: response evaluation and biomarker development. Nat Rev Clin Oncol. 2017;14(11):655-668

142. Stewart CA, Metheny H, Iida N, et al. Interferon-dependent IL-10 production by Tregs limits tumor Th17 inflammation. J Clin Invest. 2013;123(11):4859-4874.

143. Pang Y, Gara SK, Achyut BR, et al. TGF- $\beta$ signaling in myeloid cells is required for tumor metastasis. Cancer Discov. 2013;3(8):936-951.

144. Qian X, Chen H, Wu X, Hu L, Huang Q, Jin Y. Interleukin-17 acts as double-edged sword in anti-tumor immunity and tumorigenesis. Cytokine. 2017;89:34-44.

145. Pitt JM, Vétizou M, Waldschmitt N, et al. Fine-tuning cancer immunotherapy: optimizing the gut microbiome. Cancer Res. 2016; 76(16):4602-4607.

146. West NR, Powrie F. Immunotherapy not working? Check your microbiota. Cancer Cell. 2015;28(6):687-689.

147. Snyder A, PamerE, Wolchok J. Immunotherapy. Could microbial therapy boost cancer immunotherapy? Science. 2015;350(6264):1031-1032.

148. Tanaka A, Sakaguchi S. Regulatory T cells in cancer immunotherapy. Cell Res. 2017;27(1):109-118.

149. Geis AL, Fan H, Wu X, et al. Regulatory T-cell response to enterotoxigenic Bacteroides fragilis colonization triggers IL17-dependent colon carcinogenesis. Cancer Discov. 2015;5(10):1098-1109.

150. Viaud S, Saccheri F, Mignot G, et al. The intestinal microbiota modulates the anticancer immune effects of cyclophosphamide. Science. 2013;342(6161):971-976.
151. Daillère R, Vétizou M, Waldschmitt N, et al. Enterococcus hirae and Barnesiella intestinihominis facilitate cyclophosphamide-induced therapeutic immunomodulatory effects. Immunity. 2016;45(4): 931-943.

152. Xu X, Zhang X. Effects of cyclophosphamide on immune system and gut microbiota in mice. Microbiol Res. 2015;171:97-106.

153. Thiele Orberg E, Fan H, Tam AJ, et al. The myeloid immune signature of enterotoxigenic Bacteroides fragilis-induced murine colon tumorigenesis. Mucosal Immunol. 2017;10(2):421-433.

154. Christoffersen TE, Hult LT, Kuczkowska K, et al. In vitro comparison of the effects of probiotic, commensal and pathogenic strains on macrophage polarization. Probiotics Antimicrob Proteins. 2014;6(1):1-10.

155. Deng H, Li Z, Tan Y, et al. A novel strain of Bacteroides fragilis enhances phagocytosis and polarises M1 macrophages. Sci Rep. 2016;6:29401.

156. Song $\mathrm{X}$, Gao H, Lin Y, et al. Alterations in the microbiota drive interleukin-17C production from intestinal epithelial cells to promote tumorigenesis. Immunity. 2014;40(1):140-152.

157. Baecher-Allan C, Viglietta V, Hafler DA. Human CD4+CD25+ regulatory T cells. Semin Immunol. 2004;16(2):89-98.

158. Egen JG, Kuhns MS, Allison JP. CTLA-4: new insights into its biological function and use in tumor immunotherapy. Nat Immunol. 2002; 3(7):611-618.

159. Dubin K, Callahan MK, Ren B, et al. Intestinal microbiome analyses identify melanoma patients at risk for checkpoint-blockade-induced colitis. Nat Commun. 2016;7:10391.

160. Gopalakrishnan V, Spencer CN, Nezi L, et al. Gut microbiome modulates response to anti-PD-1 immunotherapy in melanoma patients Science. 2018;359(6371):97-103.

161. Sivan A, Corrales L, Hubert N, et al. Commensal Bifidobacterium promotes antitumor immunity and facilitates anti-PD-L1 efficacy. Science. 2015;350(6264):1084-1089.

162. Matson V, Fessler J, Bao R, et al. The commensal microbiome is associated with anti-PD-1 efficacy in metastatic melanoma patients. Science. 2018;359(6371):104-108

163. Frankel AE, Coughlin LA, Kim J, et al. Metagenomic shotgun sequencing and unbiased metabolomic profiling identify specific human gut microbiota and metabolites associated with immune checkpoint therapy efficacy in melanoma patients. Neoplasia. 2017;19(10): $848-855$

164. Iida N, Dzutsev A, Stewart CA, et al. Commensal bacteria control cancer response to therapy by modulating the tumor microenvironment. Science. 2013;342(6161):967-970.

165. Jin P, Wang K, Huang C, Nice EC. Mining the fecal proteome: from biomarkers to personalised medicine. Expert Rev Proteomics. 2017; 14(5):445-459.

166. Amiot A, Dona AC, Wijeyesekera A, et al. (1)H NMR spectroscopy of fecal extracts enables detection of advanced colorectal neoplasia. J Proteome Res. 2015;14(9):3871-3881.

167. Venerito M, Vasapolli R, Rokkas T, Malfertheiner P. Helicobacter pylori and gastrointestinal malignancies. Helicobacter. 2015;20(Suppl 1): 36-39.

168. Ogino S, Nishihara R, Vanderweele TJ, et al. Review article: the role of molecular pathological epidemiology in the study of neoplastic and non-neoplastic diseases in the era of precision medicine. Epidemiology. 2016;27(4):602-611.

169. Ogino S, Nowak JA, Hamada T, et al. Integrative analysis of exogenous, endogenous, tumour and immune factors for precision medicine. Gut. 2018;67(6):1168-1180.

170. Ai L, Tian H, Chen Z, Chen H, Xu J, Fang JY. Systematic evaluation of supervised classifiers for fecal microbiota-based prediction of colorectal cancer. Oncotarget. 2017;8(6):9546-9556.

171. Zhang MM, Cheng JQ, Xia L, et al. Monitoring intestinal microbiota profile: a promising method for the ultraearly detection of colorectal cancer. Med Hypotheses. 2011;76(5):670-672. 
172. Shah MS, Desantis TZ, Weinmaier T, et al. Leveraging sequencebased faecal microbial community survey data to identify a composite biomarker for colorectal cancer. Gut. 2018;67(5):882-891.

173. Jenq RR. How's your microbiota? Let's check your urine. Blood. 2015; 126(14):1641-1642.
174. Panteli JT, Forkus BA, van Dessel N, Forbes NS. Genetically modified bacteria as a tool to detect microscopic solid tumor masses with triggered release of a recombinant biomarker. Integr Biol. 2015;7(4):423-434.

175. Gardlik R, Fruehauf JH. Bacterial vectors and delivery systems in cancer therapy. IDrugs. 2010;13(10):701-706.

\section{Publish your work in this journal}

OncoTargets and Therapy is an international, peer-reviewed, open access journal focusing on the pathological basis of all cancers, potential targets for therapy and treatment protocols employed to improve the management of cancer patients. The journal also focuses on the impact of management programs and new therapeutic agents and protocols on

\section{Dovepress}

patient perspectives such as quality of life, adherence and satisfaction. The manuscript management system is completely online and includes a very quick and fair peer-review system, which is all easy to use. Visit http://www.dovepress.com/testimonials.php to read real quotes from published authors. 